\title{
An overview of information goods pricing
}

\section{Wei-Lun Chang* and Soe-Tsyr Yuan}

Department of Management Information Systems, National Chengchi University, 64, Sec. 2, Zhi-nan Rd., Wenshan, Taipei, Taiwan

E-mail: wlchang@mis.nccu.edu.tw E-mail: yuans@mis.nccu.edu.tw ${ }^{*}$ Corresponding author

\begin{abstract}
Although information economy has been the focus of considerable research, no unified and exhaustive classification model for current pricing methods exists. This work presents a novel unifying pricing framework. Each category in the framework is defined by the structural elements that accounts for its behaviour and particular aims. This work also identifies the implicit joints among categories as the basis for optimising prices (only in terms of different perspectives). The benefits of the unifying framework are that it provides a conceptual abstract model that differentiates between different pricing methods, and positions the future effectual pricing methods.
\end{abstract}

Keywords: information goods; pricing method; taxonomy model; electronic business.

Reference to this paper should be made as follows: Chang, W-L. and Yuan, S-T. (2007) 'An overview of information goods pricing', Int. J. Electronic Business, Vol. 5, No. 3, pp.294-314.

Biographical notes: Wei-Lun Chang is a $\mathrm{PhD}$ candidate in the MIS Department, National Chengchi University. Computer Science was his major in his BA, and Information Management his Major in his MS. His research areas include artificial intelligence, data/text mining, mobile computing, and information goods pricing.

Soe-Tsyr Yuan is a Professor in the MIS Department, National Chengchi University. Her research interests include service science, mobile/ubiquitous commerce, multi-agent systems, agent-based e-commerce technologies, data mining in business intelligence management, and agent-based service oriented computing.

\section{Introduction}

The information economy, defined as the exchange of information goods and services, as opposed to physical goods and services (http://www.innovation.sa.gov.au/), has been the subject of numerous investigations. This concept is utilised to characterise an economy in which information activities and the information industry play significant roles (http://www.answers.com/topic/information-economy). The information economy engenders other issues such as information cost/pricing, technology infrastructure, and information policy. The information economy is characterised by three primary tasks: information production, information consumption, and information transactions. 
Shapiro and Varian (1998a) investigated the information economy using three dimensions: information, technology, and policy (Figure 1). The information dimension encompassed concepts such as production costs, management of intellectual property and one-to-one marketing. The technology dimension consisted of the concepts of system competition, lock-in switching costs, network externalities, and standards, whereas the policy dimension comprised concepts of anti-trust and privacy.

Figure 1 Three dimensions of the information economy

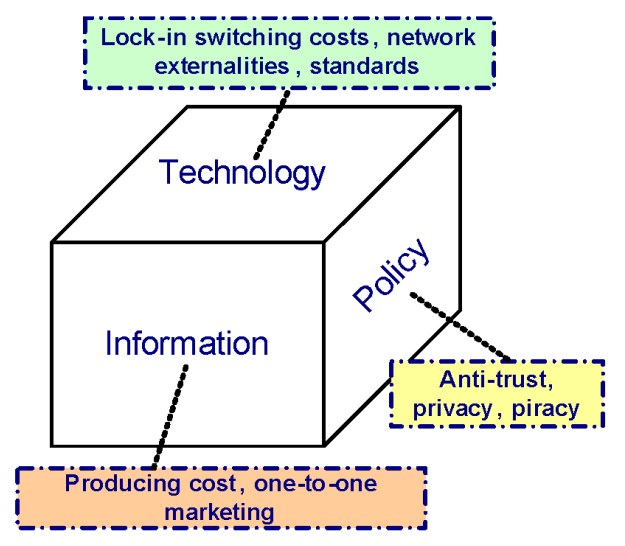

This study, which is particularly focused on the concept of information goods pricing, provides a state-of-the-art of pricing methods, and analyses the principal directions in current research. The remainder of this paper is organised as follows. Section 1 elucidates the concepts relevant to information economy and discusses the issues associated with pricing methods. Section 2 presents an overview the primary pricing models. Section 3 evaluates the relative strengths and weaknesses of these models. Section 4 outlines the areas that require further research when attempting to develop a comprehensive pricing model for complex settings.

\subsection{Information goods}

Shapiro and Varian (1998b) defined 'information goods' broadly as anything that can be digitised and encoded as a stream of bits, and transmitted over an information network. Information goods include books, movies, software programs, web pages, song lyrics, television programmes, and newspaper columns. Furthermore, information goods are characterised by high fixed production costs and extremely low reproduction costs.

Information products typically comprise three macro characteristics - they are physical (e.g., indestructibility, transmutability, and reproducibility), spatial/temporal (e.g., enhancement of competition), and contingent (e.g., real-time or near real-time) (http://econ.gsia.cmu.edu/ecommerce/Lecture\%202/). McCain (2005) recognised the economic characteristics of information products, such as transmission media (can not be bought or sold alone), uniqueness, high fixed cost, the incentive problem (minimal incentive to produce information products due to piracy), and intellectual property.

Hui and Chau (2002) proposed a classification framework for digital products based on product category and characteristics. The dimension, product category, has three subcategories: tools and utilities (e.g., Adobe Acrobat); content-based digital products 
(e.g., music, books), and online services (e.g., online consulting). The dimension product characteristics also has three subcategories: delivery mode (is the information product downloadable or always available?), granularity (is it easy to partition the information product?), and trialability (can a user try before ordering?). Table 1 presents a matrix of the two dimensions.

Table 1 Classification matrix of digital products

\begin{tabular}{llll}
\hline Category/characteristic & Tools and utilities & Content-based digital product & Online services \\
\hline Delivery mode & Download & Download & Interactive \\
Granularity & Low & High & Medium \\
Trialability & High & Low & Medium \\
\hline
\end{tabular}

Information products are characterised by no attrition (quality is not degraded over time), they can be easily copied (no additional costs when making a copy), they have network externality (word-of-mouth effects), are easily changed, and goods can be experienced before purchasing? In short, information product characteristics and cost structure (high production cost and low reproduction cost) differ significantly from those of conventional businesses. The value of information goods also varies and pricing strategies can be volatile.

\subsection{The market for information goods}

Theoretically, the market for information goods is not 'perfectly competitive'. Shapiro and Varian (1998a) identified two sustainable structures for the information goods market: dominant-firm monopoly, and differentiated products. Microsoft is a well-known example a dominant-firm monopoly, and movie/TV programmes are examples of differentiated products. Accordingly, feasible strategies for marketing information goods are differentiated based on the product (value-added to raw information) and cost leadership via economies of scale.

Additionally, tactics of first-mover would be to avoid greed and play tough. Avoiding greed indicates that a business responds to threats quickly and decisively and utilises limiting pricing strategies (e.g., differential pricing). Playing tough means that a business attempts to eliminate potential competitors by protecting intellectual property and continually innovating. Therefore, pricing and competition are the principal elements used to succeed in the information market. Companies entering the market must be aware that differential pricing is a market practice.

\subsection{Pricing issues}

Due to the unique cost structure and product characteristics (http://oz.stern.nyu.edu/ io/pricing.html) of information goods, utilising conventional pricing strategies is unfeasible, and using a differential pricing strategy is crucial to success. Varian (1995) identified two key pricing issues - price discrimination and bundling.

Generally, price discrimination attempts to optimise pricing rather than merely lowering prices. For instance, from a producer perspective (i.e., maximise profits), a producer charges different users different prices according to their Willingness-To-Pay (WTP). Figure 2 presents a picturesque clarification of this example. 
When a producer sets a high price, only those customers willing to pay the high price will purchase the product, then the profit is only US\$ 6 (Figure 2). If the price is low, customers with high and low WTP will consume and the profit will again be US\$6. However, when prices are based on customer WTP, customers with high and low WTP will purchase the product and profit will increase to US\$10. That is, differential pricing methods, such as non-linear pricing, bundling, and versioning, in existing literature attempt to maximise producer profit. A detailed description of different pricing methods is presented in Section 3. Pigou (1920) also categorised price discrimination methods into three levels: personalised pricing (first degree), versioning (second degree), and group pricing (third degree).

Figure 2 The differences among pricing methods

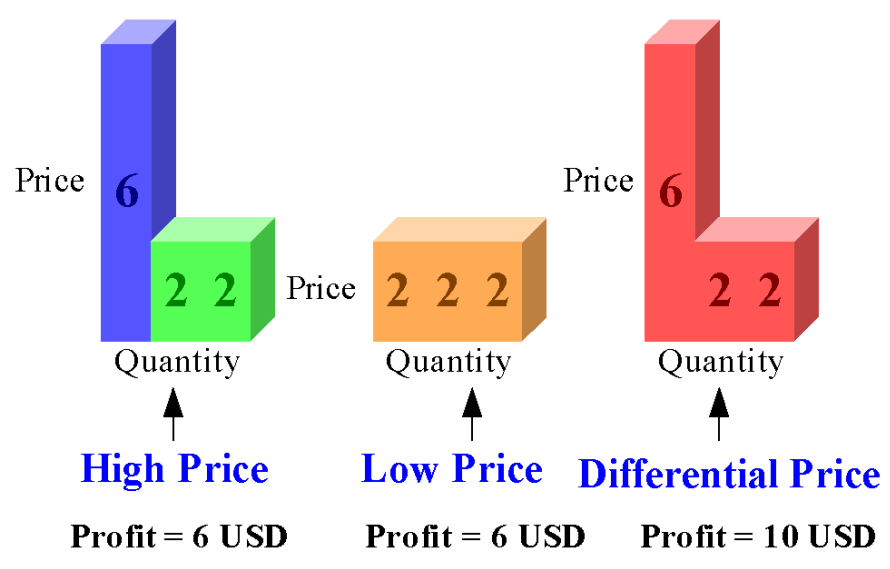

Bundling, a pricing method analysed by Varian (1995), is an approach that reduces the heterogeneity of consumer WTP. A producer can generate increased profit using bundling as average customer WTP is increased. Thus, the number of bundles, bundle strategies, and factors associated with bundling are the primary issues in bundling (Section 3 presents a detailed discussion of bundling methods). In addition to price discrimination and bundling, another significant issue is to generate a unifying framework for pricing methods that uses existing pricing perspectives and is comprehensive in complex settings.

\section{A unifying framework of pricing methods}

This section presents a novel unifying framework for pricing methods using existing pricing perspectives and an overview the primary pricing models.

Pricing taxonomy models can be used to classify pricing methods.

- Sundararajan (2004) categorises pricing methods for information goods into use-based pricing (e.g., digital music), fixed-fee (unlimited usage) pricing (e.g., online newspapers), and fixed-fee and use-based pricing (e.g., corporate software). The results also suggest a number of managerial guidelines for designing pricing schedules. 
- Stiller et al. (2000) develops a pricing classification paradigm that encompasses three dimensions: technical, research, and economic/social. The research dimension is focused on pricing theory and application. The economic/social dimension emphasises user requirements, efficiency and marketing, using pricing methods. The technical dimension underscores time/space/volume, technological requirements, and service characterisation. However, the classification model only addressed things on the surface and can not be employed when using current pricing methods.

- Jain and Kannan (2002) identify four pricing strategies for online servers: connect-time-based; search-based; subscription-fee; and, others. However, many problems are associated with these strategies.

- The connect-time-based strategy is not related to the amount of information retrieved and, thus, is unrealistic.

- With the search-based strategy, the fee paid by customers for successfully viewing/downloading material is frequently expensive.

Moreover, the variation in consumer expertise and perceived values associated with successful downloads impact the choice of pricing strategies. The subscription-fee strategy was shown to be an optimal solution for inelastic demands.

- Kannan and Kopalle (2001) propose a taxonomy model for dynamic internet pricing strategies that dynamically updates posted prices (i.e., take-it-or-leave-it pricing), auction pricing and bundle pricing. This taxonomy model has several limitations.

- The model merely focuses on the abstract level of various dynamic pricing strategies without providing detailed descriptions of the three strategies.

- The model considers consumer perspectives.

- Kannan and Kopalle omitted any discussion of information goods pricing. Consequently, this taxonomy model is of little value for pricing information goods.

In summary, each of these pricing classification models adopts a particular perspective when examining pricing methods. Although a given perspective can be further segmented into a few sub-perspectives, a unifying framework of classification models for current pricing methods is needed. Figure 3 presents the novel unifying framework proposed in this study.

Figure 3 A unifying framework for pricing methods

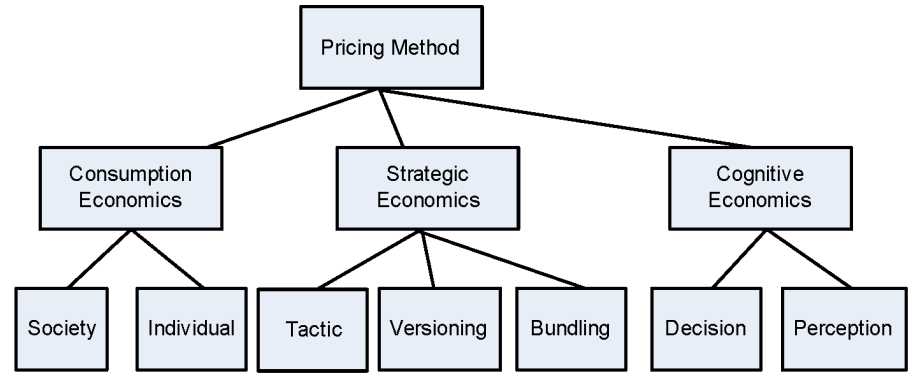


The benefits of the unifying framework are two-fold.

- the framework provides a conceptually intuitive and comprehensive classification model

- $\quad$ it suggests areas that could utilise new pricing methods.

In the following subsections, each method category is defined and their structural elements are elucidated (Figure 4). A method in a category can encompass elements that account for the method's external behaviours and specific purposes.

Figure 4 Aims of the proposed unifying framework

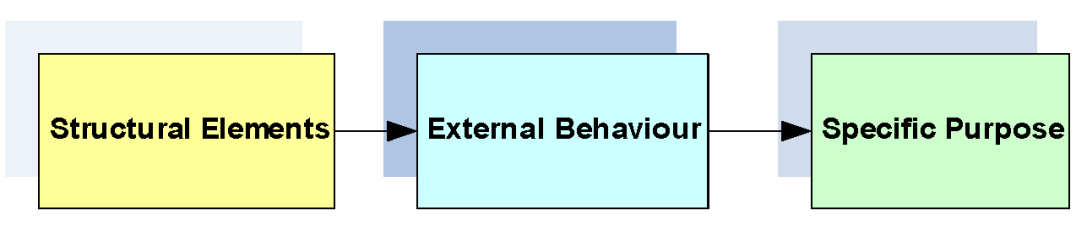

This study identifies the structural elements of each category and describes how they are related to each method (and hence its category definition). Furthermore, this study explains the common objectives for optimising prices from perspectives implied by the category definitions.

\subsection{Strategic economics}

Strategic economics put emphasis on cooperative solution between parties with conflicting interest. Such interactions are becoming an increasing focus in both the business and public environment (http://handbook.curtin.edu.au/courses/30/ 305996.html). Versioning and bundling are two branches of strategic economics which discusses pricing methods with second degree price discrimination. Strategic economics would unfold three branches as 'Tactic' and 'Versioning' and 'Bundling' which will be elaborated in the following sub-sections.

\subsubsection{Tactic}

The first category of the pricing method is Tactic, which represents the methods embodying particular pricing strategies for information goods. The general purpose of this category is to optimise prices, and thereby maximise profit. The structural elements of this category (i.e., the factors affecting pricing strategies) include information asymmetry, network externalities, complexity, competitiveness, technical strength, fundamental characteristics, and economics (Figure 4). To generate profit, different pricing strategies for information goods typically weight structural elements differently. This subsection outlines existing pricing methods.

Wang (2004) utilises three pricing strategies - individualisation, group pricing and versioning. Characteristics of information goods and network externality (e.g., network externality implies that as more people consume information goods, additional consumers will be willing to purchase such goods) were the two structural elements considered. The pricing method proposed by Jing (2000) also indicates that network externality was a key factor affecting the versioning strategy. Generally, the features of information 
products (e.g., easy to copy) account for the pricing strategies utilised (e.g., easy to copy makes versioning feasible). Conversely, network externality increases consumer willingness to experience myriad information products, thereby rendering certain pricing strategies practical. For instance, versioning partitions a mass of customers into various consumer subgroups that favour myriad product versions, whereas group pricing segments different levels of customers based network externality.

Grunenwald and Vernon (1988) identify certain pricing strategies, such as market skimming, market penetration, competitive pricing, cost pricing, and value pricing. Their analytical results demonstrated that economy, technique and competition factors were the three principal structural elements affecting pricing schemes. Dasgupta and Das (2000) also indicate that competitor pricing was a significant factor worthy of consideration when shaping a pricing strategy. Generally, the economic parameter empowers strategies to maximise profit and minimise costs in cost pricing strategies. The technique element considers technological stability and maturity, whereas the competition parameter then drives the integrity of competitor information when market penetration and competitive pricing strategies are adopted.

Brooks et al. (1999) determine that pricing strategy complexity was a major factor affecting profit. For example, their pricing model, which used one parameter, includes pure bundling and linear pricing; the pricing model with two parameters comprised a two-part tariff (i.e., customers pay a subscription fee and a per-paper price) and mixed bundling (with mixed bundling, consumers buy individual items at price A each, or all $\mathrm{N}$ items for price B). Additionally, Sundararajan (2004) analyses a nonlinear pricing scheme with $\mathrm{N}$ parameters. Without losing generality, an increased level of strategic complexity generates increased profits obtained by the corresponding pricing methods.

Lakhal and H'Mida (2005) propose a pricing model based on formal propositions and mathematical analysis, which allows a firm to maximise its value-added, competitive advantages perceived by customers, and its market share for a product distributed to a global market via the internet. Additionally, the most significant contribution is that it exploits perceived value to maximise several objectives simultaneously and identifies a pricing policy in increasingly competitive and global environments.

Huang (2001), who examines the issue of unfair pricing on the internet, indicated that information asymmetry (information asymmetry occurs when one party has more/better information than another party in economics) was a factor excluding network externalities, resulting in either poor subsidisation of the rich or aggregate loss in consumer welfare. The proposition predicted that the led and late majority consumers are charged using a demand curve and most early consumers are charged via a supply curve, suggesting that information asymmetry imposes insufficient information for consumers or producers of certain advantages.

The other elements that can impact profit include customisation (Koifman et al., 2004) and negotiation (Aron et al., 2004). Negotiation can generate win-win outcomes for sellers and buyers, whereas customisation impacts parameters such as cost considered in cost-based pricing strategies - customised products cost more than non-customised products.

Figure 5 presents a summary of structural elements (macro-level perspectives) in the Tactic category, in which pricing methods are used to maximise profit. That is, these approaches (i.e., their external behaviours) attempt to perform well when faced with uncertainty and variability based on adopted macro-level perspectives. The structural 
elements then encompass network externalities, competition, information asymmetry, and the economy.

Figure 5 Structural elements considered in 'Tactic' category

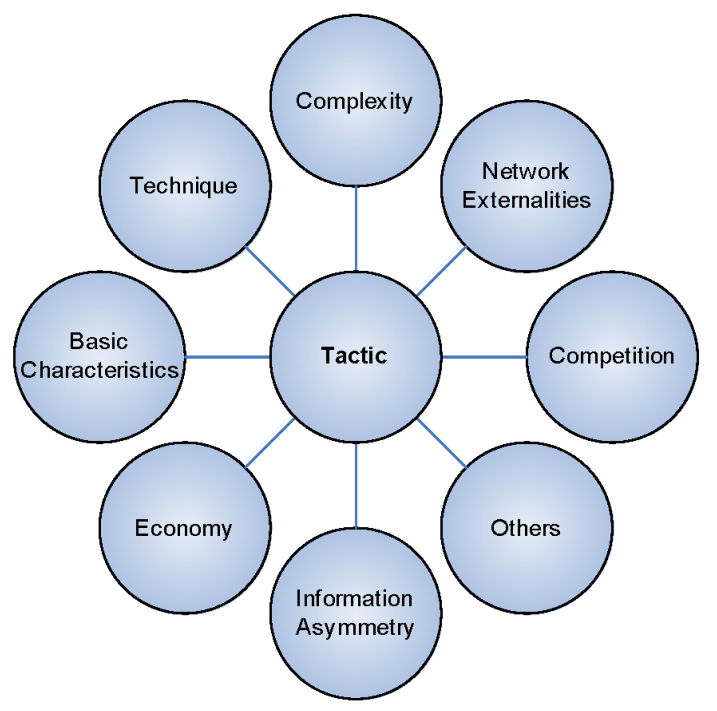

\subsubsection{Versioning}

The Versioning category comprises pricing methods grounded in producer perspectives, the major function of which is to optimise prices by vertically differentiating the goods markets. Varian (1997) indicates that an optimal versioning solution, via examining total surplus from an economic perspective, is the best pricing regime for information goods. In this category, two orientations emerged, internal factors (factors intrinsic to the creation and delivery of a product) and external factors (factors of no relevance to pro) (Figure 6).

Figure 6 Structural elements considered in the 'Versioning' category

\section{External}
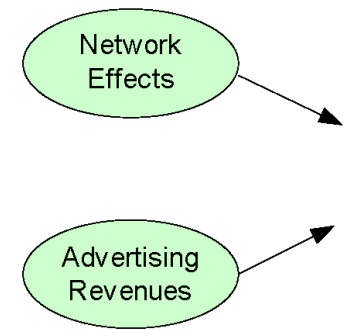

Internal

Delay

Convenience

Comprehensive

Manipulation

Community

Annoyance

Speed

Data Processing

User Interface

Image Resolution

Support

\section{External}

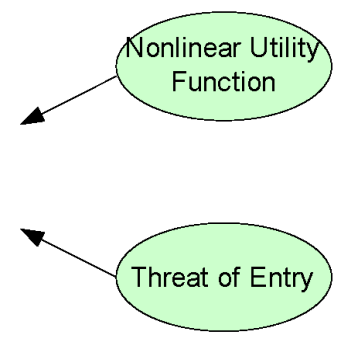

.

When vertically differentiating a market, three versions, in general, is an appropriate versioning policy when market segmentation is ambiguous. Additionally, producers have four practical concerns. 
- prepare a product that can be versioned

- differentiate the market high end first

- ensure that versioned products can be viewed by consumers

- utilise Goldilocks pricing (i.e., the notion of Goldilocks pricing is based on 'extremeness aversion', which means that consumers tend to choose the mid-range when offered high-end and low-end pricing) for producers in the absence of additional information, except having three versions.

For the structural elements of internal factors, Shapiro and Varian (1998b) identify an appropriate number of versions in terms of delay factors, convenience, comprehensiveness, manipulation, community, annoyance, speed, data processing, user interface, image resolution, and support. For instance, for a product that is not convenient, is delivered slowly and requires complex manipulations, the number and differential levels of versions should be short and separated well.

Bhargava and Choudhary (2001) identify several externals as key structural elements that influence the versioning paradigm, which are network effects, advertising revenues, non-linear utility function, and threat of entry. For instance, high advertising revenues differentiate popular versions from unacceptable versions; high threat of entry requires various versions to segment a market and differentiate a product to win the competition.

Figure 6 presents a summary of the structural elements (producer perspectives) utilised in the Versioning category, in which pricing methods consider for-profit optimisation within a family of goods. The external behaviour of these methods attempts to perform well when facing a market of goods vertically differentiated according to producer perspectives. There are two types of structural elements (internal and external) that can be considered simultaneously to increase the comprehensiveness of pricing methods.

\subsubsection{Bundling}

The Bundling category comprises pricing methods that are grounded in producer perspectives; however, their major function is to optimise prices in terms of packaging goods in a variety of configurations, thereby reducing heterogeneity in consumer valuations. Generally, the structural elements in this category have two orientations: qualitative factors and quantitative modelling.

The orientation of qualitative factors

Varian (1995) notes that product bundling is a profitable result of reducing the heterogeneity of consumer WTP. A producer can sell at an average WTP by creating product bundles. That is, consumer heterogeneity is a qualitative factor that determines the scale of profits. For example, when consumers are extremely heterogeneous, separating WTP and determining appropriate product bundles are difficult tasks.

Bakos and Brynjolfsson (2000), who investigate factor competition in Bundling indicated that large bundles may generate significant competitive advantages. Moreover, the act of bundling information goods makes it difficult for an incumbent tougher to compete. Furthermore, bundling reduces competitor incentive to innovate. 
In summary, competition is a qualitative factor driving the number of bundles and integrity of bundling information.

\section{The orientation of quantitative modelling}

Some studies have developed mathematical models to explore methods of attaining appropriate bundles, bundle prices, or number of information goods in bundles.

For instance, Altinkemer and Jaisingh (2002) determine that profits increase when the number of information goods in bundles increases. In their model, consumer surplus was assessed by analysing the bundles and demand. The quality level (e.g., a bundle with a high number of information goods has increased quality) and consumer types (e.g., different customers value bundles differently and a higher type customer is willing to pay more) were also considered.

Certain assumptions were required for the model to maximise profit via Bundling: consumer surplus for buying a large bundle is higher than the sum for buying sub-bundles, and a elevated bundle price resulted in low surplus. Their analytical results demonstrated that maximum profits could be generated by satisfying the constraints (e.g., non-negative surplus) and assumptions. Their analytical results also suggested that profits grew linearly by increasing the number of information goods in bundles, and that consumer perceptions of various bundles affected their WTP. Moreover, bundles with both information goods and physical goods may increase total profits as the marginal cost of such bundles is lower than the sales of physical goods in bundles when the marginal cost of physical goods exceeds a threshold.

Chang et al. (2003) developed an algorithm for bundling appropriate goods dynamically and efficiently. This algorithm utilised two-phase path pruning to search the top-K bundles, each of which consists of $\mathrm{M}$ components with pair-wise inter-component relations. Accordingly, the speed of searching the top $\mathrm{K}$ bundles was fast and the costs associated with production and transaction were reduced simultaneously (e.g., bundling reduces the costs of manufacturing, packaging, and shipping goods, thus increasing transaction efficiency).

The Online Bundle-Purchasing Problem (OBPP) is a new computational challenge created by e-commerce technology (Buffett and Spencer, 2004). The OBPP considers the time frame when maximising a buyer's overall satisfaction. Buyer's satisfaction was formalised using a multi-attribute utility approach that considers buyer attitudes toward quality, reputation, and risk. At certain times, a buyer must decide whether to buy a bundle of currently available items or take a risk and let the opportunity pass and wait for future opportunities. Their work attempted to maximise satisfaction when a customer purchased a bundle offered during certain time frames. Their analytical results revealed that a decision procedure that exploits time frames yields a higher expected utility than a naïve decision procedure that simply pursues the best bundle.

Somefun and Poutré (2003) developed a framework of an integrated recommender system to identify a collection of (sub)bundles and their dynamic prices using customer preferences. In their study, customer preferences were formulated as maximum consumer utility determined by perceived value, purchasing cost, and searching cost of transactions. Thus, the number of goods in the bundle with maximum utility could be identified using customer perspectives. The optimal bundle price was then calculated by subtracting from the total price of each product in the bundle an adjustable amount, which is a discount based on the number of information goods in the bundle, i.e., the discount increases relative to the number of goods in the bundle). 
There were many practical applications of bundling in various industries. Kivisaari and Luukkainen (2003) apply the content service bundling in telecommunication industry. A new content-based pricing model on the internet was presented in terms of controlling the consumption of content, and assisting producers to choose bundles and prices. On the other hand, Altinkemer (2001) investigates bundling e-banking services such as e-bills and e-business in the banking industry, offering flexible and adjustable bundles to consumers. Moreover, the usage patterns could be shared among consumers that were then empowered to make good choices of bundles to purchase.

Figure 7 presents a summary of structural elements (producer perspectives) considered in the bundling category, in which pricing methods take into account for-profit optimisation across different families of goods. The external behaviours of these models aim to perform well when faced with horizontal packaging in the goods market and reductions in heterogeneity of consume valuations according to the producer perspectives adopted. There are qualitative and quantitative factors in this category. Each method adopts a different perspective in identifying the optimal price when creating a beneficial method (for both consumers and producers) for bundling.

Figure 7 Structural elements considered in the 'Bundling' category

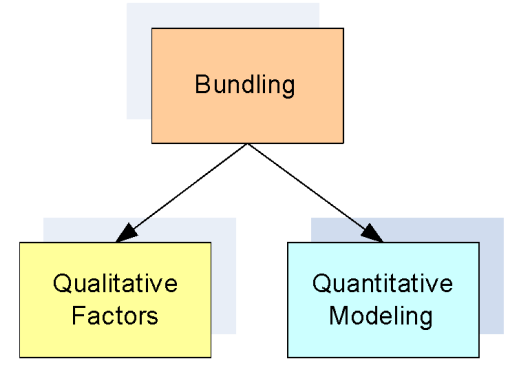

\subsection{Consumption economics}

Consumption economics is the branch of economics that focuses on consumers' behaviour as they locate economics resources to satisfy their wants. Studies of consumption economics investigate how and why society and individuals consume goods and services, and how this affects society and human relationships (Burk, 1968). Consumption economics would unfold two branches as 'Society' and 'Individual', respectively which will be elaborated in the following sub-sections.

\subsubsection{Society}

Some studies have investigated the social (governmental) perspectives associated with information goods. This category, called Society, is integrated into the unifying framework. This category is an alternative perspective for deciding price via four structural elements - law, fines, taxes, and subsidies. Ultimately, this category optimises prices by maximising social welfare.

Chen and Png (2003) propose a pricing method that considers both price and copyright enforcement while attempting to maximise social welfare (e.g., the welfare or well-being of a society. and to provide a wide range of social services and benefits to individual citizens). Three structural elements are considered from a governmental 
perspective - fines for copying information, taxes on the copying medium, and subsidies for legitimate purchases. The primary results were

- an increase in protection that affects welfare more negatively than reductions in price

- taxes are superior to fines

- $\quad$ subsidies comprise the optimal policy.

That is, reducing taxes encourages companies to adjust their prices, resulting in better social welfare than decreasing fines. Subsidising legitimate purchases is the optimal policy as this mechanism maximises social welfare. Generally, governmental policies that focus on penalties alone do not optimise social welfare.

Conversely, Odlyzko (2003) demonstrates that from a social perspective, privacy is a structural element that is sacrificed in differential pricing. For example, when producers offer different prices for the product, consumer information would then allow producers to determine individual consumer WTPs. Thus, governments will likely play an increasing role in establishing protection rules for private information pricing.

Other elements that may affect social welfare are market structure, elasticity of demand, marginal cost, economies of distribution, and use of complex menus (Papandrea et al., 2003). The principal goal of the work by Papandrea et al. was to analyse the factors on welfare implication for bundling products. For example, consumer surplus decreases due to complex pricing menus, which increase consumer difficulty when choosing the best option. Therefore, the solution that underlines an appropriate bundling strategy (e.g., pure bundling, mixed bundling, unbundling) based on the social welfare perspective is to provide comparative information for price menus.

Figure 8 summarises the structural elements (social perspectives) considered in the Society category, in which pricing methods should maximise social welfare. In other words, the external behaviour of these approaches is focused on performing well when faced with retaining particular cultural organisations.

Figure 8 Structural elements considered in the 'Society' category

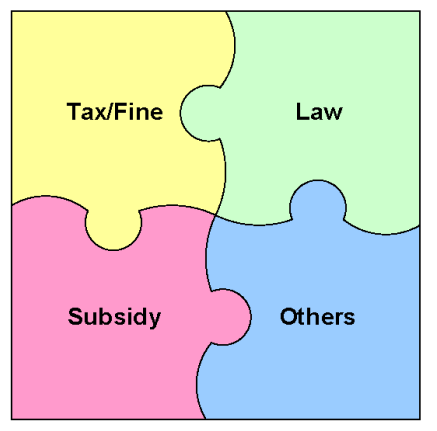

\subsubsection{Individual}

The Individual category represents a class of pricing methods that emphasise individual perceptions - perceived value - regarding information goods. The goal of this category is to optimise prices by determining customer WTP. Generally, the structural elements in this category are quantitative measurement, qualitative factors and information utilisation. 
For quantitative measurement (emphasising product features addressed when computing WTP, the Multi-Attribute Utility Theory (MAUT) proposed by Schäfer (2001) was employed to measure a user interests and construct rules from experiments. For instance, multiple attributes for assessing the value of digital cameras are: quality of image, flash, viewfinder, operation time, and handling. When combined, these attributes alter WTP measurements when optimising prices.

In addressing qualitative factors (focusing on qualitative elements that affect perception of WTP and Willingness-To-Accept (WTA)), Simonson and Drolet (2004) examine WTP/WTA (e.g., willingness-to-accept is the minimum amount producers are prepared to 'sell' goods or services for) in terms of an anchoring effect (e.g., buyers compare prices or products against a reference price or product, that is, the comparison result is usually weighted toward the anchor, thereby creating an anchor bias) and endowment effect (e.g., the endowment effect is a hypothesis suggesting that people value a product with established property-rights much more than those with no established property-rights). Their analytical results revealed that when WTP/WTA is uncertain, the anchoring effect impacts the initial perception of value under uncertainty, and the endowment effect influences the uncertainty in desire to buy.

For information utilisation, which emphasises the variance in user perceptions at different times, such as in the early and late stages, Huang (2005) segments consumers as short-term and long-term when computing WTP. Most early consumers paid less when they lacked detailed product information. Conversely, most late consumers paid more when well informed about a product (combined with increased product demand due to the network externality effect). That is, information asymmetry and network externalities were two structural elements that impact consumer perceptions and can drive extraction of consumer surplus and the process of differentiating prices.

Figure 9 presents a summary of the structural elements (consumer-perception perspectives) in the Individual category, in which pricing methods consider WTP). The aim of these methods (i.e., their external behaviour) is to perform well when translating certain stimulations into organised experience according to consumer-perception perspectives. The structural elements then comprise the following five factors: information asymmetry, network externality, endowment effect, anchor effect, and MAUT.

Figure 9 Structural elements considered in the 'Individual' category

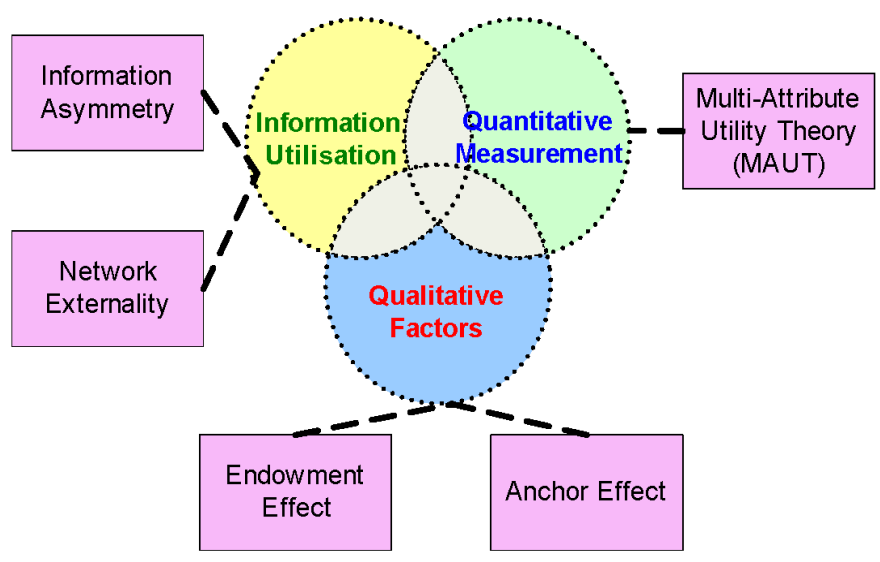




\subsection{Cognitive economics}

Cognitive economics investigates bounded procedural rationality, social influence on individual decision making, and the dynamics of adaptive social systems. It aims to take into account the cognitive processes of individuals in economic theory, both at the level of the agents and of their dynamic interactions (Bourgine and Nadal, 2004). Cognitive economics would unfold two branches as 'Perception' and 'Decision', respectively, which will be elaborated in the following sub-sections.

\subsubsection{Perception}

Price fairness is an interesting issue for investigating from a psychological perspective. Hence, a Perception category for pricing methods is created. This category is a branch of the cognitive economics, and emphasises the factors influencing sense of price fairness. The purpose of this category is to optimise prices by achieving price fairness when considering psychological factors. The category's structural elements have pricing factors and non-pricing factors.

To analyse pricing factors (e.g., considering market demand, market competition, etc.), Xia et al. (2004), develop a conceptual framework and in which various elements were examined, and purchase intention was a factor influencing consumer perception of unfair prices. In this conceptual framework, the cognitive and affective factors are the major variables in perceived price fairness. Purchase intention (cognitive) and negative emotions (affective), in general, result in various actions (e.g., no action, self-protection, and revenge) manifested in perceived price fairness. For example, when a customer's purchase intention is low, the customer typically withdraws the purchase (self-protection), which is indicative of perceived price unfairness.

Conversely, three pricing factors regarding seller/market information are addressed by Miyazaki (2003), such as seller pricing setting, seller perceptions of competitor prices and seller perception of buyer prices. Nevertheless, "seller perceptions of buyer prices" is the sole structural element from the psychological perspective. Seller perception of buyer prices indicates how sellers perceive and respond to prices set by buyers during price negotiations. Sellers can, therefore, evaluate optimal prices in terms of perceived fairness/unfairness.

In investigating non-pricing factors (e.g., considering product availability, product quality, etc.), Miyazaki (2003) identifies product availability as a crucial structural element driving price fairness from a psychological perspective. Increased product availability is suggestive of stable market demand. Stable demand subsequently implies that buyers perceive price fairness and that prices are close to optimal.

Figure 10 presents a summary of the structural elements (mental psychology perspectives) in the Perception category, in which pricing methods take the consumer into consideration when achieving price fairness. These methods attempt to perform well by ensuring bias/deception-free based on some psychological perspectives. Structural elements then include types of pricing and non-pricing that can be integrated when deriving optimal price. Furthermore, additional factors can be discovered in the future by applying psychology. 
Figure 10 Structural elements considered in the 'Perception' category

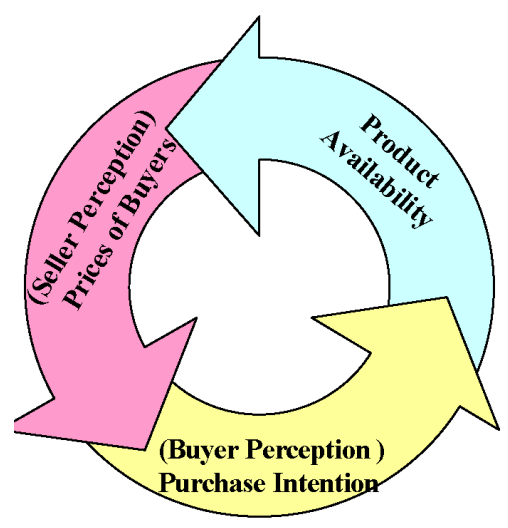

\subsubsection{Decision}

The Decision category is utilised to explore the behavioural perspective in pricing methods based on behavioural economics (behavioural Economics, the combination of psychology and economics, is used to investigate the machinations of markets). This category has two goals

- differentiate between rational and irrational consumers

- discover critical structural elements (e.g., intelligence, time, and mood) - both of which affect decision-making during product pricing.

To differentiate rational and irrational consumers, consumer behaviour employs two perspectives, static and dynamic (Miravete, 2003). Consumers are guided by their expectations in static manner (i.e., irrational) and learn after making an initial mistake in a dynamic manner (i.e., rational).

Irrational consumers make purchase decisions intuitively in a static manner, and rational consumers establish deliberate judgments by learning through mistakes. Producers can determine prices according to the characteristics of rational and irrational consumers. For example, producers may generate increased profit by setting high prices for irrational consumers, and develop a win-win strategy by using reasonable prices for rational consumers.

Kahneman (2003) devises a framework for cognitive systems that contains intuition- and reason-based subsystems. The intuitive process (static) is fast, effortless, automatic, and emotional. Conversely, the reasoning process (dynamic) is slow, effortful, controlled, and neutral. Irrational consumers are located in the intuition subsystem in that they act fast and behave emotionally. Conversely, rational consumers are located in the reasoning subsystem in that they make decisions slow and neutrally.

To identify the category of structural elements, some theories were examined in the framework, such as prospect theory (the Prospect Theory describes how individuals evaluate losses and gains), framing effect (the Framing Effect is a change in preferences between options as a function of the variation of frames), and attribute substitution. Analytical results indicated that time pressure and mood affect the intuitive process, suggesting that such people make purchase decisions intuitively under pressure. 
Additionally, intelligence affects the reasoning process (i.e., intelligent people reason about their purchase decisions deliberately and leisurely).

Conversely, Agarwal and Chatterjee (2003) perceive decision difficulty in terms of an alternative structural element that affects decisions when selecting from a menu of bundles, the number of unique services between competing bundles, and the perceived similarity of bundles. Their analytical results revealed that large bundles with many unique services and similar bundles render decisions more difficult when consumers encounter similar prices for these bundles.

Figure 11 presents a summary of the structural elements (behavioural perspectives) in the decision category, in which the goal of pricing methods is to maximise profit. The aim of the external behaviour of these methods is to perform well when faced with analysing a judgement reached by a consumer (rational or irrational) according to the behavioural perspectives adopted. The structural elements then include stimuli in the judgement decision process, such as intelligence, time, mood, and decision difficulty.

Figure 11 Structural elements considered in the 'Decision' category

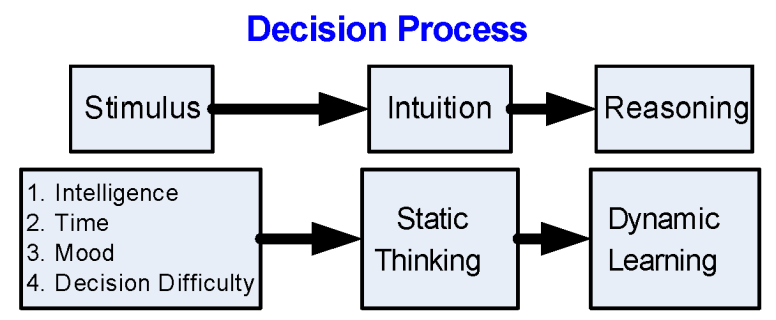

\section{Discussion}

Various differences and commonalities in pricing paradigms for information goods were examined. As for shared characteristics, the goal of each method was not necessarily to maximise profits, but rather to optimise pricing from different perspectives. Differences in terms of functional structural elements were extracted via categories in the unifying framework.

The strengths and weaknesses of methods were further analysed. The categories of Tactic, Perception and Decision were used investigate psychological factors. However, these methods merely regarded the psychology of consumers based on qualitative considerations. Conversely, the categories of Society, Individual, Versioning, and Bundling are grounded in mathematical models developed using different viewpoints, such as those of consumers, producers, and government. Each method is skewed toward a specific perspective. For instance, the Perception category only regards the consumer perspective.

Rather, this study synthesises and analyses studies in terms of objectives, structural elements, and beneficiaries (e.g., consumers, suppliers, or government). The beneficiaries are stakeholders upon whom current pricing research focuses. The taxonomy model is a comprehensive classification approach that considers numerous perspectives when designing pricing approaches. Nevertheless, each perspective considers only some pricing issues for certain confined problems (Table 2). Real-world problems frequently require consideration of numerous perspectives. 
Table 2 Details and expansion of unifying framework

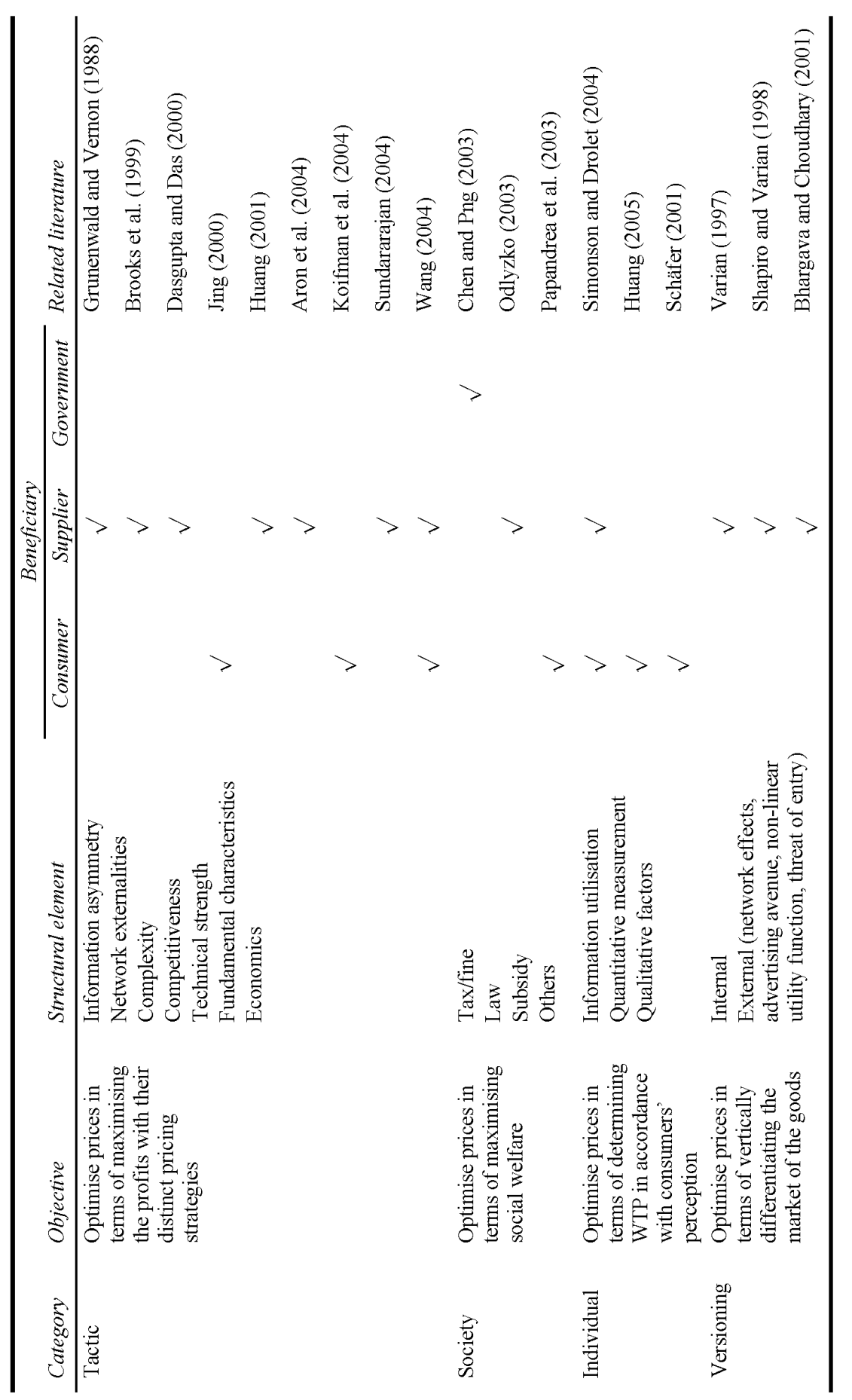


Table 2 Details and expansion of unifying framework (continued)

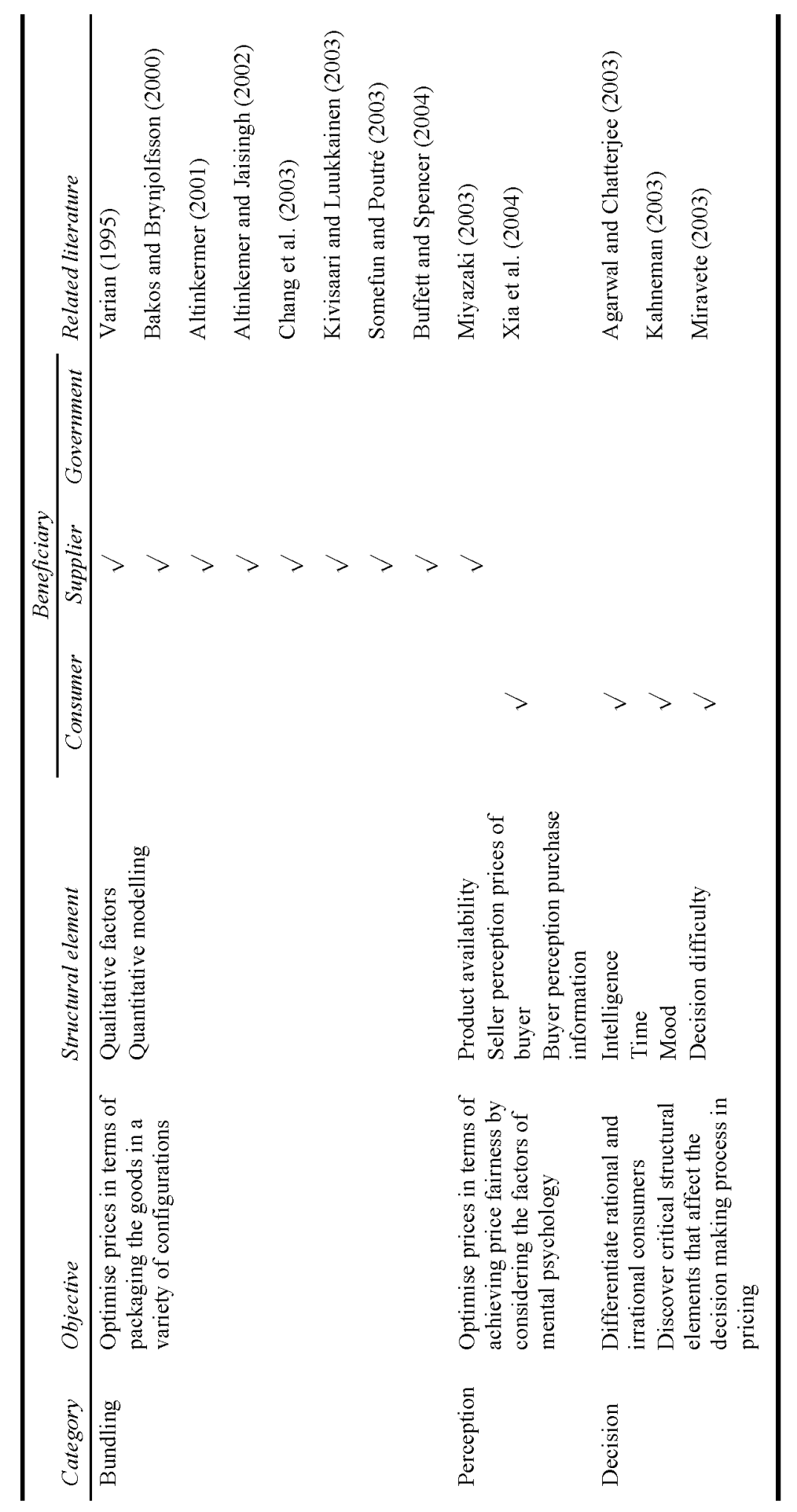


Novel pricing methods combined with synthesised perspectives can be devised to tackle real pricing issues. For example, the macro (versioning) and micro (bundling) perspectives can be considered simultaneously, thereby benefiting both producers and consumers. Hence, a Synthesis category, which combines pricing issues addressed in the other categories, was created to optimise pricing.

Compared with existing pricing taxonomy models, the proposed taxonomy model clearly assigns pricing methods to categories; this process will help in the creation of future pricing methods). In the proposed model, structural elements are unfolded for each pricing method category; these elements are used to identify the external behaviour required to achieve their respective purposes. Additionally, these elements can also be attached for method enhancement according to the affiliation of a new method.

The taxonomy model also recognises the strengths, weakness, opportunities, and threats of specific pricing methods. For example, when a new pricing method is located in several categories, the approach may not be too skewed or biased (strength), but rather too complex (weakness). The comparison of existing methods with the proposed method identified the differences and advantages/disadvantages (opportunities). Overall, the taxonomy model can compete with existing pricing methods (threats).

\section{Conclusion}

Pricing information goods is crucial and significant in an information economy. This study examined current pricing approaches and identified the critical structural elements for each method. A novel and comprehensive unifying framework is presented that improves current loosely coupled classification models. The unifying framework has seven categories: Tactic, Society, Perception, Individual, Cognition, Decision, Versioning and Bundling. This study examined the structural elements driving the particular behaviours and purposes in each category.

The taxonomy model provides a framework for recognising the strengths, weaknesses, and opportunities in, and threats to, existing and future pricing methods. It indicates that a realistic problem often requires the consideration of combined perspectives which means novel pricing methods with synthesised perspectives could be devised to tackle the reality. A synthesis category is then believed to be a new research area worthy of further investigation in the future.

In other words, method benchmarking with the taxonomy model is straightforward and this paper conduct comparison for a new method in justifying its competitive opportunities. This unifying framework not only provides a structured understanding of existing information goods pricing methods but also identifies fruitful directions for future research.

\section{Acknowledgements}

We would like to thank the following scholars who provided valuable suggestions in improving our research work: Professor Ming-Hui Huang (IM, NTU), Professor Hsiu-Ju Yen (IM, NCU), Professor Carol, Wei-Yun Hsu (IS, CityU), and other professors from ACME06 conference. 


\section{References}

Agarwal, M. and Chatterjee, S. (2003) 'Complexity, uniqueness, and similarity in between-bundle choice', The Journal of Product and Brand Management, Vol. 12, Nos. 6-7, pp.358-376.

Altinkemer, K. (2001) 'Bundling e-banking services', Communication of ACM, Vol. 44, No. 6, June, pp.45-47.

Altinkemer, K. and Jaisingh, J. (2002) 'Pricing bundled information goods', The Proceeding of the 4th IEEE Int'l Workshop on Advanced Issues of E-Commerce and Web-Based Information Systems (WECWIS), June 26-28, Newport Beach, California, USA, pp.89-96.

Aron, R., Sundararajan, A. and Siva Viswanathan, S. (2004) 'Intelligent agents in electronic markets for information goods', Decision Support Systems, November, pp.764-786.

Bakos, Y. and Brynjolfsson, E. (2000) 'Bundling and competition on the internet', Marketing Science, Vol. 19, No. 1, Winter, pp.63-82.

Bhargava, H.K. and Choudhary, V. (2001) 'Information goods and vertical differentiation', Journal of Management Information Systems, Vol. 18, pp.89-106.

Bourgine, P. and Nadal, J.P. (2004) Cognitive Economics: An Interdisciplinary Approach, Springer, Cheltenham, UK.

Brooks, C.H., Fay, S., Das, R., MacKie-Mason, J.K., Kephart, J.O. and Durfe, E.H. (1999) 'Automated strategy searches in an electronic goods market: learning and complex schedules', ACM EC-99, November, pp.31-40.

Buffett, S. and Spencer, B. (2004) 'A decision procedure for bundle purchasing with incomplete information on future prices', International Journal of Electronic Commerce, Vol. 8, No. 4, Summer, pp.131-144.

Burk, M. (1968) Consumption Economics: A Multidisciplinary Approach, John Wiley \& Sons, Inc., New York.

Chang, Y.C., Li, C.S. and Smith, J.R. (2003) 'Searching dynamically bundled goods with pairwise relations', The Proceedings of ACM Electronic Commerce (EC'03), Dan Diego, California, USA, June 9-12, pp.135-143.

Chen, Y.N. and Png, I. (2003) 'Information goods pricing and copyright enforcement: welfare analysis', Information Systems Research, Vol. 14, No. 1, March, pp.107-123.

Dasgupta, P. and Das, R. (2000) 'Dynamic pricing with limited competitor information in a multi-agent economy', Cooperative Information Systems, Lecture Notes in Computer Science, Proceedings of the Fifth International Conference on Cooperative Information Systems (CoopIS), Eilat, Israel, September, pp.299-310.

Grunenwald, J.P. and Vernon, T.T. (1988) 'Pricing decision making for high-technology products and services', Journal of Business and Industrial Marketing, Vol. 3, No. 1, Winter, pp.61-70.

Huang, M.H. (2001) 'Unfair pricing in the information economy: implications for public policy', Conference Proceedings of American Marketing Association, Chicago, Illinois, pp.364-365.

Huang, M.H. (2005) 'Unequal pricing in the information economy: implications for consumer welfare', Journal of Business Ethics, Vol. 56, pp.305-315.

Hui, K.L. and Chau, Y.K. (2002) 'Classifying digital products', Communications of the ACM, Vol. 45, No. 6, June, pp.73-79.

Jain, S. and Kannan, P.K. (2002) 'Pricing of information products on online servers: issues, models, and analysis', Management Science, Vol. 48, No. 9, September, pp.1123-1142.

Jing, B. (2000) 'Versioning information goods with network externalities', Proceedings of the 21 International Conference on Information Systems, Brisbane, Queensland, Australia, pp.1-12.

Kahneman, D. (2003) 'Maps of bounded rationality: psychology for behavioral economics', American Economic Review, Vol. 93, No. 5, pp.1449-1475. 
Kannan, P.K. and Kopalle, P.K. (2001) 'Dynamic pricing on the internet: importance and implications for consumer behavior', International Journal of Electronic Commerce, Vol. 5, No. 3, Spring, pp.63-83.

Kivisaari, E. and Luukkainen, S. (2003) 'Content-based pricing of services in the mobile internet', Internet and Multimedia Systems and Applications, Honolulu, Hawaii, Vols. 13-15, pp.479-483.

Koifman, G., Shehory, O. and Gal, A. (2004) 'Negotiation-based price discrimination for information goods', $A A M A S$ '04, July 19-23, New York, pp.679-686.

Lakhal, S.Y. and H'Mida, S. (2005) 'A pricing model for a new product sold over the internet', Int. J. Internet Marketing and Advertising, Vol. 2, Nos. 1-2, pp.56-77.

McCain, R.A. (2005) Essential Principles of Economics: A Hypermedia Text. Chapter 16, http://william-king.www.drexel.edu/top/prin/txt/EcoToC.html.

Miravete, E.J. (2003) 'Choosing the wrong calling plan? Ignorance and learning', American Economic Review, Vol. 93, March, pp.297-310.

Miyazaki, A.D. (2003) 'The psychology of pricing on the internet', Psychology and Marketing, Vol. 20, No. 6, pp.471-476.

Odlyzko, A. (2003) 'Privacy, economics, and price discrimination on the internet', ACM, Fifth International Conference on Electronic Commerce (ICEC2003), pp.355-366.

Papandrea, F., Stoeckl, N. and Daly, A. (2003) 'Bundling in the Australian telecommunications industry', Australian Economic Review, Vol. 36, No. 1, pp.41-54.

Pigou, A.C. (1920) The Economics of Welfare, 4th ed., Macmillan, London, UK.

Schäfer, R. (2001) 'Rules for using multi-attribute utility theory for estimating a user's interests', Proc. 9th GI-Workshop: ABIS-Adaptivität und Benutzermodellierung in interaktiven Softwaresystemen, Dortmund, Germany, October.

Shapiro, C. and Varian, H.R. (1998a) Information Rules; A strategic guide to the network economy, Harvard Business School Press, Boston, MA.

Shapiro, C. and Varian, H.R. (1998b) 'Versioning: the smart way to sell information', Harvard Business Review, November-December, pp.106-114.

Simonson, I. and Drolet, A. (2004) 'Anchoring effects on consumers' willingness-to-pay and willingness-to-accept', Journal of Consumer Research, Vol. 31, December, pp.681-690.

Somefun, D.J.A. and La Poutré, J.A. (2003) 'Bundling and pricing for information brokerage: customer satisfaction as a means to profit optimization', The Proceedings of Web Intelligence, IEEE Computer Society, Halifax, Canada, pp.182-189.

Stiller, B., Reichl, P. and Leinen, S. (2000) 'Pricing and cost recovery for internet services: practical review, classification, and application of relevant models', Economic Research and Electronic Networking, Vol. 2, No. 1, January, pp.149-171.

Sundararajan, A. (2004) 'Nonlinear pricing of information goods', 2nd International Industrial Organization Conference, April, pp.1660-1673.

Varian, H. (1995) 'Pricing information goods', Proceedings of the Symposium on Scholarship in the New Information Environment, Harvard Law School, May 2-3.

Varian, H. (1997) 'Versioning information goods', The Economics of Digital Information (tentative), Discussion Paper, MIT Press, Cambridge, MA.

Wang, K.L. (2004) 'Pricing strategies for information products: a review', IEEE International Conference on e-Commerce Technology for Dynamic E-Busines (CEC04EAST), Beijing, China, September 13-15, pp.345-348.

Xia, L., Monroe, K.B. and Cox, J.L. (2004) 'The price is unfair! A conceptual framework of price fairness perceptions', Journal of Marketing, Vol. 68, October, pp.1-15. 